\title{
Radiotherapy in acromegaly: the argument against
}

\author{
Ariel L. Barkan \\ Pituitary and Neuroendocrine Center, University of \\ Michigan, Ann Arbor, MI, USA
}

(Received 14 February 2002; accepted 6 June 2002)

External pituitary irradiation (XRT) has been used as a therapeutic modality in patients with acromegaly for the past 100 years. Multiple studies have demonstrated the slow but inexorable decline of plasma $\mathrm{GH}$ for as long as 20-25 years after the procedure, with some $70-90 \%$ of patients ultimately achieving plasma GH levels below $5 \mu \mathrm{g} / 1(1 \mu \mathrm{g}=2.6 \mathrm{mU})$. Also, XRT either shrinks pituitary tumours or, at the very least, effectively prevents them from enlarging. Thus, XRT offers both biochemical and morphological benefits to patients with acromegaly. However, the downside of XRT is not negligible. Up to $50-60 \%$ of patients develop hypopituitarism, and some have optic nerve damage or ophthalmoplegia. The ensuing cerebrovascular damage raises the risk of a cerebrovascular accident 2-4-fold. Additionally, there is a small (1-2\%) but devastating risk of developing radiation-induced malignant brain tumours, and the neurocognitive impairments (memory deficits, depression, etc.) appear to be significant. The morbidities of acromegaly (arthropathy, cardiomyopathy, sleep apnea, etc.) also continue to progress during the long interval between the procedure and the biochemical 'cure'. Despite these problems, the balance between the risks and benefits of XRT was clearly tilted towards the latter as long as surgical techniques remained crude and the pharmacological modalities nonexistent. Most importantly, the belief that GH levels below 5-10 $\mu \mathrm{g} / 1$ were biologically harmless (Christy, 1982) implied that radiotherapy was a highly effective therapeutic modality.

The development and wide availability of IGF-1 assays have changed the definition of what constitutes good control of acromegaly. On purely theoretical grounds, measurement of a trophic, instead of a target, hormone seems to be misplaced. Indeed, one would not claim 'cure' of Cushing's disease or a TSH-producing tumour based on 'normal' ACTH or TSH concentrations as long as cortisol or thyroxine levels remain elevated. Clinical manifestations of acromegaly correlate very well with plasma IGF-1 but very poorly with plasma GH (Clemmons et al., 1979). Plasma IGF-1 remains elevated in $10-40 \%$ of the patients

Correspondence: Dr Ariel L. Barkan, 3920 Taubman Center, Box 0354, University of Michigan Medical Center, Ann Arbor, MI 48109-0354, USA. Tel.: 734615 6964; Fax: 734936 9240;

E-mail: abarkan@umich.edu whose GH was decreased below 2-2.5 $\mu \mathrm{g} / 1$ (Barrande et al., 2000; Peacey et al., 2001), and the mortality in such patients is still increased by a similar percentage (Bates et al., 1993; Orme et al., 1998) despite statistical 'similarity' with the general population. Even newly diagnosed and clinically active patients may present with a full-blown clinical picture of acromegaly despite having apparently 'normal' mean daily GH but elevated IGF-1 levels (Dimaraki et al., 1999). Finally, the recent data on the GH receptor antagonist, pegvisomant, proved beyond a doubt that normalization of plasma IGF-1 leads to a dramatic improvement in the clinical picture of acromegaly (van der Lely et al., 2001). These considerations led to the virtually universal acceptance of plasma IGF-1 as the most appropriate and accurate index of disease control.

How efficacious is XRT when measured according to this parameter? The reported percentages of IGF-1 normalization vary widely between studies due to inhomogeneity and the limited size of the study groups, the variable durations of followup, and the use of different IGF-1 assays. Fortunately, the technique of XRT is almost standard around the world and, unlike surgery, is largely operator independent. The meta-analytical approach compensates for the heterogeneity of patient populations in different studies and smoothes the fluctuation in the outcomes. However, many, if not most, of the published series do not provide individual data and use either mean or median followup as a time frame. This introduces an additional level of difficulty in interpreting the 'summed-up' data, especially when they are related to the time course of normalization of hormone parameters.

In Table 1, data are summarized from all but two of the published series reporting the efficacy of XRT in terms of IGF-1 normalization in acromegaly, including a personal communication from Dr Philippe Jaquet from Marseille. Two studies were not included in the final analysis. In the first (Ciccarelli et al., 1993), $80 \%$ of the allegedly normal IGF-1 values were accompanied by frankly elevated mean daily GH levels, up to $50 \mu \mathrm{g} / 1$, casting grave doubt on the validity of the IGF-1 assay employed in that study. In the other excluded study (Biermasz et al., 2000), more than a third of the patients prior to XRT had plasma IGF-1 levels overlapping the normal range, and another third did not have IGF-1 measured before XRT but were found to have normal IGF-1 values at the very first post-XRT follow-up within 2 years. Thus, many, or perhaps most, patients in that study had normal IGF-1 because of curative surgery rather than XRT.

The overall frequency of normalization of IGF-1 after conventional XRT was $36 \%$. In the series with a duration of either mean or median follow-up less than 7 years, the efficacy was $29 \%$ (61 of 210) and in those with follow-up longer than 10 years it rose 
Table 1 Efficacy of conventional XRT

\begin{tabular}{|c|c|c|c|}
\hline Author (Year) & $\begin{array}{l}\text { Follow-up mean or } \\
\text { median (years) }\end{array}$ & $N$ & $\begin{array}{l}\text { Normal } \\
\text { IGF-1 }\end{array}$ \\
\hline Giannella-Neto et al. (1988) & 5 & 8 & 2 \\
\hline Barkan et al. (1997) & $6 \cdot 8$ & 38 & 2 \\
\hline Van der Lely et al. (1997) & 7 & 37 & 0 \\
\hline Thalassinos et al. (1998) & $>10$ & 14 & 4 \\
\hline Swearingen et al. (1998) & $6 \cdot 7$ & 45 & 19 \\
\hline Powell et al. (2000) & $5 \cdot 2$ & 31 & 14 \\
\hline Barrande et al. (2000) & 15 & 47 & 37 \\
\hline Bezerra et al. (2000) & 4 & 51 & 20 \\
\hline Alfaro et al. (2000) & 10 & 91 & 38 \\
\hline Gutt et al. (2001) & $12 \cdot 8$ & 41 & 14 \\
\hline Cozzi et al. (2001) & 14 & 49 & 8 \\
\hline Epaminonda et al. (2001) & 12 & 67 & 37 \\
\hline Jaquet (pers. commun.) & 7 & 40 & 4 \\
\hline Total & & 560 & 199 \\
\hline
\end{tabular}

to $39 \%$ (138 of 350 ). However, the number of patients lost to follow-up increases significantly with time in all published series, and those followed for 15-20 years usually constitute about $10 \%$ of the total number, limiting the reliability of the analysis. More importantly, poorly controlled patients are more likely to die prematurely, leaving the 'cured' ones available for a long-term analysis, thus providing a skewed and falsely optimistic impression of the long-term efficacy of XRT.

What about the relatively new modality of stereotactic radiosurgery (SRS)? Its theoretical advantage over conventional XRT is the ability to deliver a very large dose of radiation to a sharply defined area in a single treatment. However, analysis of the old literature casts doubt on the advantage of more massive radiation doses. Littley et al. (1990) reported results of low-dose conventional XRT (2000-4000 rad), and Jadresic et al. (1987) reported the efficacy of the interstitial radiation using ${ }^{90} \mathrm{Y}$ seed implantation into the tumour bed (50 000-150 $000 \mathrm{rad)}$ ). Plasma GH levels below $2.5 \mu \mathrm{g} / 1$ were reached in $26 \%$ and $30 \%$ after 5 years and in $49 \%$ and $53 \%$ after 10 years in the two series, respectively. Even though there are differences in the radiobiology of the two modalities, the identical outcomes do not support the notion of 'more is better'. Lüdecke et al. (1989) provided the only available peer-reviewed comparison of conventional XRT vs. a proton beam technique in small numbers of patients. After 5 years of follow-up, plasma GH levels below $4.5 \mu \mathrm{g} / 1$ were achieved in $47 \%$ of the former and $38 \%$ of the latter group, an almost identical result. Table 2 summarizes all the available reports of the gamma-knife or linear accelerator techniques that used IGF1 as the efficacy parameter.

Overall, only $33 \%$ of patients achieved normal IGF-1 levels after SRS. To compare the efficacies of the two modalities (XRT $v s$. SRS) one has to take into account the shorter follow-up in
Table 2 Efficacy of stereotactic radiosurgery

\begin{tabular}{llrc}
\hline & $\begin{array}{l}\text { Follow-up mean or } \\
\text { median (years) }\end{array}$ & $N$ & $\begin{array}{l}\text { Normal } \\
\text { IGF-1 }\end{array}$ \\
\hline Voges et al. (1996) & $>0 \cdot 5$ & 14 & 0 \\
Mokry et al. (1999) & 4 & 16 & 4 \\
Laws and Vance (1999) & $0 \cdot 5-9$ & 36 & 9 \\
Kim et al. (1999) & 1 & 2 & 0 \\
Jackson and Noren (1999) & $1-4$ & 10 & 6 \\
Vladyka et al. (2000) & 2 & 91 & 39 \\
Powell (2000) & 5 & 10 & 3 \\
Landolt et al. $(2000)$ & $0 \cdot 5-2 \cdot 5$ & 31 & 13 \\
Shin et al. (2000) & 3 & 6 & 4 \\
Barausse et al. (2001) & 11 & 9 & 1 \\
Epaminonda (2001) & 4 & 16 & 3 \\
Morange-Ramos et al. (2001) & 4 & 38 & 8 \\
Total & & 270 & 90 \\
\hline
\end{tabular}

the latter series. Including only the series with a mean or median follow-up between 2 and 10 years (to provide maximal advantage to the SRS data), $33 \%$ of the patients in the SRS series (77 of 232 ) and $29 \%$ after XRT (99 of 341) achieved the goal of a normal IGF-1, again an almost identical number. Some authors (Jackson \& Noren, 1999; Laws \& Vance, 1999; Landolt et al., 2000) have mentioned that normalization of IGF-1 in their 'responders' occurred faster than what would have been expected had XRT been used instead. This clinical impression is intriguing but requires additional studies for objective confirmation. Speed of action aside, the higher efficacy of SRS vs. XRT does not seem to be supported by the existing data. Local toxicities of SRS also have to be taken into account; for example, ophthalmoplegia and optic nerve damage (Lüdecke et al., 1989; Laws et al., 1999; Barausse et al., 2001; Morange-Ramos et al., 2001) occur much more often with SRS than with XRT.

Thus, the efficacy of radiation therapy, when judged by the strict criterion of normalization of IGF-1, is significantly less than was reported in the past when success was measured by GH levels. The existing data on SRS fail to confirm its higher efficacy compared with conventional XRT. The introduction of modern pharmacological compounds, somatostatin analogues in particular, also weakened the argument for the use of XRT as a 'tumour shrinking' modality, as these drugs not only normalize plasma IGF-1 in the majority of patients but also effectively prevent tumour regrowth for as long as they are administered. The imminent introduction of the GH receptor antagonist, pegvisomant, more or less assures normalization of IGF-1 in every patient. Thus, both biochemical and morphological goals of therapy can be achieved pharmacologically without exposing the patients to increased risks of hypopituitarism, vascular damage, blindness, ophthalmoplegia and secondary tumour formation, which are part and parcel of radiation therapies. 
The use of radiotherapy may still be justified in patients whose tumours are unresponsive to somatostatin and continue to grow. In societies with limited health budgets, new and expensive drugs are likely to be unaffordable and radiation may remain the only available alternative. One can also argue that radiation may allow eventual termination of drug therapy in a subset of patients, and a medico-economic analysis of such an approach may be useful. Accurate knowledge of the true efficacy of radiation therapy is needed for a realistic approach to all these quandaries.

In summary, the widespread use of radiotherapy in the past was due to a lack of other, more effective therapies such as sophisticated surgical techniques and pharmacological preparations. Its supposedly high efficacy was asserted on the basis of an erroneous assumption that plasma $\mathrm{GH}$ in the 5-10 $\mu \mathrm{g} / 1$ range had no appreciable deleterious effects (Christy, 1982). Recent developments in imaging and surgical techniques allow us to detect the presence or regrowth of a pituitary tumour with accuracy and to remove it with a high degree of precision and success. Novel pharmacological preparations reliably prevent tumour regrowth and are capable of normalizing plasma IGF-1, the real culprit of the clinical syndrome, in almost all surgically uncured cases. Thus, the era of the indiscriminate use of radiotherapy in acromegaly has come to an end.

About 2500 years ago, Hippocrates formulated a therapeutic dictum: 'What drugs do not cure, that the knife cures. What knife doesn't cure, that the fire cures. What fire doesn't cure, must be called incurable.' In patients with acromegaly, radiation, the modern equivalent of Hippocratic fire, should now assume its proper place: a treatment of last resort.

\section{References}

Alfaro, J.J., Lucas, T., Lamas, C., Estrada, J., Garcia-Uria, J., Magaelon, R. \& Barcelo, B. (2000) Conventional pituitary irradiation after transsphenoidal surgery in acromegaly: report of 91 cases. 11th International Congress of Endocrinology, Sydney. P1274.

Barausse, M., Dallabonzana, P., Attanasio, R., Asnaghi, D., Lodrini, S. \& Cozzi, R. (2001) Failure of radiotherapy in acromegaly. 83rd Meeting of the Endocrine Society, Denver. Abstract P2-166.

Barkan, A.L., Halasz, I., Dornfeld, K.J., Jaffe, C.A., Friberg, R.D., Chandler, W.F. \& Sandler, H.M. (1997) Pituitary irradiation is ineffective in normalizing plasma insulin-like growth factor I in patients with acromegaly. Journal of Clinical Endocrinology and Metabolism, 82, 3187-3191.

Barrande, G., Pittino-Lungo, M., Coste, J., Ponvert, D., Bertagna, X., Luton, J.P. \& Bertherat, J. (2000) Hormonal and metabolic effects of radiotherapy in acromegaly: long-term results in 128 patients followed in a single center. Journal of Clinical Endocrinology and Metabolism, 85, 3779-3785.

Bates, A.S., Van't Hoff, W., Jones, J.M. \& Clayton, R.N. (1993) An audit of outcome of treatment in acromegaly. Journal of Medicine, 86, 293-299.

Bezerra, A.K., Seidenberger, K., Charf, A., Knoepfelmacher, M., Liberman, B., Musolino, N.C. \& Bronstein, M.D. (2000) Radiotherapy for acromegaly: long-term results. 11th International Congress of Endocrinology, Sydney. P1334.
Biermasz, N.R., van Dulken, H. \& Roelfsema, F. (2000) Long-term follow-up results of postoperative radiotherapy in 36 patients with acromegaly. Journal of Clinical Endocrinology and Metabolism, 85, 2476-2482.

Christy, N.P. (1982) Choosing the best treatment for acromegaly. Journal of the American Medical Association, 247, 1320.

Ciccarelli, E., Valetto, M.R., Vasario, E., Avataneo, T., Grottoli, S. \& Camanni, F. (1993) Hormonal and radiological effects of megavoltage radiotherapy in patients with growth hormone-secreting pituitary adenoma. Journal of Endocrinological Investigation, 16, 565-572.

Clemmons, D.R., Van Wyk, J.J., Ridgway, E.C., Kliman, B., Kjellberg, R.N. \& Underwood, L.E. (1979) Evaluation of acromegaly by radioimmunoassay of somatomedin-C. New England Journal of Medicine, 301, $1138-1142$.

Cozzi, R., Barausse, M., Asnaghi, D., Dallabonzana, D., Lodrini, S. \& Attanasio, R. (2001) Failure of radiotherapy in acromegaly. European Journal of Endocrinology, 145, 717-726.

Dimaraki, E.V., Jaffe, C.A., DeMott-Friberg, R., Chandler, W.F., Gorelick, J. \& Barkan, A.L. (1999) Micromegaly: active acromegaly with normal GH levels. Implications for diagnostic and follow-up criteria. 81st Meeting of the Endocrine Society, San Diego. Abstract P3-658.

Epaminonda, P., Motti, E.D., Ventrella, L., Giugni, E., Cappiello, V., Ferrante, E., Beck-Peccoz, P., Faglia, G. \& Arosio, M. (2001) Effects of gamma-knife on GH and IGF-1 levels in acromegaly. 83rd Meeting of the Endocrine Society, Denver. Abstract P2-185.

Giannella-Neto, D., Wajchenberg, B.L., Mendonca, B.B., Almeida, S.F., Macchione, M. \& Spencer, E.M. (1988) Criteria for the cure of acromegaly: comparison between basal growth hormone and somatomedin $\mathrm{C}$ plasma concentrations in active and non-active acromegalic patients. Journal of Endocrinological Investigation, 11, $57-60$.

Gutt, B., Hatzack, C., Morrison, K., Pollinger, B. \& Schopohl, J. (2001) Conventional pituitary irradiation is effective in normalising plasma IGF-1 in patients with acromegaly. European Journal of Endocrinology, 144, 109-116.

Jackson, I.M. \& Noren, G. (1999) Role of gamma-knife radiosurgery in acromegaly. Pituitary, 2, 71-77.

Jadresic, A., Jimenez, L.E. \& Joplin, G.F. (1987) Long-term effect of ${ }^{90} \mathrm{Y}$ pituitary implantation in acromegaly. Acta Endocrinologica, 115, 301-306.

Kim, M.S., Lee, S.I. \& Sim, J.H. (1999) Gamma-knife radiosurgery for functioning pituitary microadenoma. Stereotactic and Functional Neurosurgery, 72, 119-124.

Landolt, A.M., Haller, D., Lomax, N., Scheib, S., Schubiger, O., Siegfried, J. \& Wellis, G. (2000) Octreotide may act as a radioprotective agent in acromegaly. Journal of Clinical Endocrinology and Metabolism, $\mathbf{8 5}, 1287-1289$

Laws, E.R. Jr \& Vance, M.L. (1999) Radiosurgery for pituitary tumors and craniopharyngiomas. Neurosurgical Clinics of North America, $\mathbf{1 0}$, 327-336.

van der Lely, A.J., de Herder, W.W. \& Lamberts, S.W. (1997) The role of radiotherapy in acromegaly. Journal of Clinical Endocrinology and Metabolism, 82, 3185-3186.

van der Lely, A.J., Hutson, R.K., Trainer, P.J., Besser, G.M., Barkan, A.L., Katznelson, L., Klibanski, A., Herman-Bonert, V., Melmed, S., Vance, M.L., Freda, P.U., Stewart, P.M., Friend, K.E., Clemmons, D.R., Johannsson, G., Stavrou, S., Cook, D.M., Phillips, L.S., Strasburger, C.J., Hackett, S., Zib, K.A., Davis, R.J., Scarlett, J.A. \& Thorner, M.O. (2001) Longterm treatment of acromegaly with pegvisomant, a growth hormone receptor antagonist. Lancet, 358, 1754-1759. 
Littley, M.D., Shalet, S.M., Swindell, R., Beardwell, C.G. \& Sutton, M.L. (1990) Low-dose pituitary irradiation for acromegaly. Clinical Endocrinology, 32, 261-270.

Lüdecke, D.K., Lutz, B.S. \& Niedworok, G. (1989) The choice of treatment after incomplete adenomectomy in acromegaly: proton versus high voltage radiation. Acta Neurochirurgica, 96, 32-38.

Mokry, M., Ramschak-Schwarzer, S., Simbrunner, J., Ganz, J.C. \& Pendl, G. (1999) A six year experience with the postoperative radiosurgical management of pituitary adenomas. Stereotactic and Functional Neurosurgery, 72, 88-100.

Morange-Ramos, I., Taieb, D., Vallette-Kasic, S., Regis, J., Dufour, H., Jaquet, P. \& Brue, T. (2001) Evaluation of gamma-knife radiosurgery for secreting pituitary adenomas: an 8-year experience in 73 patients. 7th International Pituitary Congress, Phoenix. Abstract 70.

Orme, S.M., McNally, R.J., Cartwright, R.A. \& Belchetz, P.E. (1998) Mortality and cancer incidence in acromegaly: a retrospective cohort study. United Kingdom Acromegaly Study Group. Journal of Clinical Endocrinology and Metabolism, 83, 2730-2734.

Peacey, S.R., Toogood, A.A., Veldhuis, J.D., Thorner, M.O. \& Shalet, S.M. (2001) The relationship between 24-hour growth hormone secretion and insulin-like growth factor 1 in patients with successfully treated acromegaly: impact of surgery or radiotherapy. Journal of Clinical Endocrinology and Metabolism, 86, 259-266.

Powell, J.S., Wardlaw, S.L., Post, K.D. \& Freda, P.U. (2000) Outcome of radiotherapy for acromegaly using normalization of insulin-like growth factor 1 to define cure. Journal of Clinical Endocrinology and Metabolism, 85, 2068-2071.

Shin, M., Kurita, H., Sasaki, T., Tago, M., Morita, A., Ueki, K. \& Kirino, T. (2000) Stereotactic radiosurgery for pituitary adenoma invading the cavernous sinus. Neurosurgery, 3, 2-5.

Swearingen, B., Barker, F.G. 2nd, Katznelson, L., Biller, B.M., Grinspoon, S., Klibanski, A., Moayeri, N., Black, P.M. \& Zervas, N.T. (1998) Longterm mortality after transsphenoidal surgery and adjunctive therapy for acromegaly. Journal of Clinical Endocrinology and Metabolism, 83, $3419-3426$.

Thalassinos, N.C., Tsagarakis, S., Ioannides, G., Tzavara, I. \& Papavasiliou, C. (1998) Megavoltage pituitary irradiation lowers but seldom leads to safe GH levels in acromegaly: a long-term follow-up study. European Journal of Endocrinology, 138, 160-163.

Vladyka, V., Liscak, R., Simonova, G., Chytka, T., Novotny, J. Jr, Vymazal, J., Marek, J., Hana, V. \& Vavros, D. (2000) Radiosurgical treatment of hypophyseal adenomas with the gamma knife: results in a group of 163 patients during a 5-year period. Casopis Lekaru Ceskych, 139, 757-766.

Voges, J., Strum, V., Deuss, U., Traud, C., Treuer, H., Schlegel, W., Winkelmann, W. \& Muller, R.P. (1996) LINAC-radiosurgery (LINACRS) in pituitary adenomas: preliminary results. Acta Neurochirurgica, 65, 41-43. 